\title{
Digital Transformation in Marketing through a Customer Knowledge Management approach for Startups and SMEs: An EdTech Startup Case Study
}

\author{
Menatalla Kaoud ${ }^{1}$, Noha A. Alaa El Dine ${ }^{2}$ \\ School of Business Administration, Nile University, Egypt
}

\begin{abstract}
.
Technologies transform marketing organizations; and the key challenge for startups and Small and Medium Enterprises (SMEs) would be to exploit the potential of digital transformation is by having a holistic management approach towards Knowledge Management $(\mathrm{KM})$ in the digital context. This paper addresses a central question from a resource-based perspective: how startups and Small and Medium Enterprises with inadequate capabilities and limited resources drove digital transformation in marketing? Customer Knowledge Management (CKM) is an integration between the approaches of Knowledge Management and Customer Relationship Management (CRM). This paper examines the evolving role of Data Science in relation to Marketing for effective Customer Knowledge Management in startups and SMEs. Adopting a case study methodology in EdTech startup based in Egypt, this paper suggests technological tools that help startups and SMEs with limited resources and capabilities take advantage of Data Science in relation to Marketing and extract valuable customer knowledge to improve CRM effectiveness. The case study also shed light on relevant organizational factors that could help such organizations align the CRM business processes with IT infrastructure. This research provides some guidance, from organizational perspective, to startups and SMEs in their digital transformation in marketing.
\end{abstract}

Keywords: Digital Transformation, Customer Knowledge Management, CRM, Marketing, Data Science 


\section{Introduction}

The leverage of technologies and digital transformation is a key challenge for startups and SMEs. The key challenge for startups and SMEs to exploit the potential of digital transformation is by having a holistic management approach towards Knowledge Management in the digital context (Vassileva, 2017; Kaoud, 2018). Successful digital transformations require companies to foster new organizational capabilities (Matt et al., 2015; Li et al., 2018). Further research could support firms by providing guidance on the assessment of their existing technological capabilities and on procedures to evaluate their current options and on how the alignment of IT strategies with other functional and operational strategies can be conducted in practice from organizational perspective (Matt et al., 2015; Kaoud, 2018). Research should establish further evidence on how entrepreneurs of SMEs with inadequate capabilities and limited resources drove digital transformation in their companies (Li et al., 2018). Existing research in entrepreneurship has largely neglected the role of digital technologies in entrepreneurial pursuits (Nambisan, 2017). Little attention was made to the role of big data in marketing activities (Rejeb, A., et al., 2020). This paper aims to answer the following question: From a resource-based perspective, how startups and SMEs with inadequate capabilities and limited resources drove digital transformation in marketing? This paper examines the evolving role of Data Science in relation to Marketing for effective Customer Knowledge Management in startups and SMEs. Adopting a case study methodology in EdTech startup based in Egypt, this paper suggests technological tools that could fit smoothly within the capabilities of startups and SMEs to take advantage of Data Science in relation to Marketing and extract valuable customer knowledge to improve CRM effectiveness. The case study also shed light on relevant organizational factors that could help them align the CRM business processes with IT infrastructure. This paper provides some guidance, from organizational perspective, to startups and SMEs in their digital transformation in marketing.

At first, a review of the literature presents relevant elements concerning digital transformation in marketing and Customer Knowledge Management. Subsequent sections present the theoretical framework, the research methodology, the case study and the research findings. The paper concludes with a summary, the research contributions, a critical reflection, and an outlook on further research possibilities.

\section{Digital Transformation in Marketing}

In this study, Digital Transformation is defined as transformation "precipitated by a transformational information technology" (Lucas et al., 2013, p. 372). Such transformation entails fundamental changes in business processes (Venkatraman, 1994), operational routines (Chen et al., 2014), and organizational capabilities (Tan et al., 2015). Digital transformation underlines the impact of IT on organizational structure, routines, information flow (Dehning et al., 2003), and organizational capabilities to accommodate and adapt to IT (Cui \& Pan, 2015). Accordingly, digital transformation emphasizes more the technological root of IT (Lucas et al., 2013) and the alignment between IT and businesses (Venkatraman, 1994). To fully take advantage of IT, companies need to build not only IT capabilities but also 


\section{3rd International Academic Conference on MANAGEMENT and ECONOMICS}

complementary capabilities such as IT human capability or new service delivery capabilities (Aral \& Weill, 2007).

This paper focuses on digital transformation in marketing. According to Dholakia et al. (2010), the increasing globalization of markets is strongly associated with the increased information-producing, information manipulating, information-distributing, and informationconsuming technologies. These are considered the most important contemporary transformative processes which lead companies to change their traditional marketing activities and organizational structures. Information is transformed into a corporate asset and its acquisition, management, and distribution are tasks that marketing should perform effectively and efficiently (Piercy, 1985; Achrol \& Kotler,1999; Luggen, 2004) especially in a dynamic and knowledge rich environment. Knowledge about customers' behavior, preferences, challenges, and interests are becoming an important source of competitive advantage (Beijerse, 1999; Salmador \& Bueno, 2007).

\section{Customer Knowledge Management and CRM Effectiveness}

Customer Knowledge Management is defined as a process of capture and/or creation, sharing and dissemination, acquisition, and application of Customer Knowledge (Dalkir \& Liebowitz, 2011) to create value for the organization and its customers (Parirokh, et al., 2009). Customer Knowledge is defined as a dynamic and necessary combination of experiences, values, information scenarios, ideas and expertise, which is created and observed in the transaction and exchange processes between the organization and its customers (Blosch, 2000). Customer Relationship Management and Knowledge Management are two management approaches with different disciplinary roots and perspectives but integrating them to manage Customer Knowledge has the potential to produce great synergies (Stefanou et al., 2003). CRM is an approach with increased strategic significance which aims to manage customer related knowledge (Karakostas et al., 2005). Marketing, Sales and Customer Service are the company's primary functions with a high degree of direct customer interaction and knowledge-intensive (Porter, 1985), making them the main targets for the Customer Relationship Management. The relevant business processes are the campaign management, lead management, offer management, contract management, complaints and service management, and opportunity management (Schmid, 2001).

The metrics commonly used by companies to measure and monitor CRM performance include customer satisfaction, customer loyalty, acquisition costs, defection rate, retention rate and other indicators (Winer, 2001; Mithas et al., 2005). In this paper, the authors present technological tools that help startups and SMEs take advantage of Data Science in relation to Marketing and extract valuable customer knowledge to improve CRM effectiveness. A number of studies have proven that CKM application enhance the company performance (Salomann et al., 2005; Kaoud, 2017) and competitiveness (Zhao et al., 2008). CKM could help organizations better understand its customers (Gibbert et al., 2002; Parirokh et al., 2009) allowing them to enhance their marketing strategies and to increase their sales (Lei \& Tang, 2005). CKM could support organizations in improving their customer service with the aim of achieving customer satisfaction and retention (Garrido-Moreno \& Padilla-Meléndez, 2011). 


\section{3rd International Academic Conference on MANAGEMENT and ECONOMICS}

Moreover, customization of products and services is expected from customers due to their knowledge that organizations possess big data (Gončarovs, 2017). This is typically achieved by exploiting Data Mining (DM) techniques, exploring patterns about customers, and consequently achieve effective CRM.

\section{Data Science and CKM for Startups and SMEs}

The Data Science term coincides with the term Big Data. Big Data simply put is made up of raw "little data." Generally, these little data give deep personal insight into a consumer's personal and buying profile, and the consumer's behaviors (Barutçu, 2017). Customer is at the heart of any business. Recently, Marketing has become a field for experiments with Big Data looms (Bendle \& Wang, 2016). Today, SMEs and marketers are challenged with information about customers from different sources such as social media, mobile devices and internet surfing (Soroka et al., 2017) leading to what is called Big Data. When BD is properly interpreted and managed, marketers are open to an array of opportunities to properly manage the Customer Knowledge.

It is critical that customer-focused companies are required to offer knowledge that customers demand, administer the knowledge that customers circulate to the company and manages knowledge about customer (Campbell, 2006). Obviously, Social Media analytics have opened a new array for big data analytics to enhance marketing strategies. Facebook and Twitter gave consumers the chance to like, follow, and comment spontaneously with their peers about their favorite, or least favorite, products, and brands (Gantz \& Reinsel, 2012; Uğur \& Turan, 2018). Zeng \& Glaister (2018) stated that companies armed with the insights generated by BD could be more agile, adaptable, and highly responsive to business needs and unexpected opportunities. Big data analytics supports firms in the extraction of significant consumers' insights to support marketing-related decisions (e.g., Google Cloud and Microsoft Azure) (Pantano et al., 2019).

SMEs are a powerful agent for industrial growth and undoubtedly, overall economic development. (Ogbuokiri et al., 2015). Earlier, the term Big Data or Knowledge Management was often associated with big brands such as Google, Amazon, Microsoft, etc. As stated by Deloitte (2018), advancement of technology such as cloud computing and Software-as-aService (SaaS) made the access for Small and Medium Enterprises viable and feasible. Thus, enabling SMEs to manage the data flow and streamline their operations to support in delivering a better experience to the customer. In general, some characteristics are needed for SMEs to deploy Data Science reflected in Big data analytics. As stated by Ogbuokiri et al. (2015) first, flexibility and choice are key, a big-data solution for small businesses must allow them to only select the capabilities that fits their needs and align with the systems in place. Second, simplicity, a big-data solution must be easy to deploy. Lastly, cost must be relevant and priced right for the needs and only the capabilities that will be used by SMEs. The real challenge as indicated is about choosing the right tools and the scalable ones to support the nature, and business growth of SMEs (Ogbuokiri et al., 2015). Later in the case study we will demonstrate how startups and SMEs can benefit as well from knowledge management and utilize big data for value creation. It might be true that SMEs might not be able to develop 
their own suite of cloud-based collaboration or AI-powered call centers, but they can capitalize and adapt knowledge to benefit from such technologies (Deloitte, 2020).

\section{Theoretical Framework: The Resource Based View}

Customer knowledge is a vital organizational resource that organizations could manage in order to improve innovation, and support research and development (Sofianti, et al., 2009). From a Resource Based View (Penrose, 1959; Wernerfelt, 1984), Customer Knowledge could be a valuable and rare asset for companies allowing them to respond quickly to customer needs and to achieve competitive advantage (Zhao et al., 2008). Sustainable competitive advantage comes from resources and capabilities, controlled by the company, that are valuable, rare, and not substitutable. These resources and capabilities could be considered as sets of tangible and intangible assets; including business management skills, organizational processes and routines, and the information and knowledge that it controls (Barney et al., 2001). In this perspective, this study intends to present the technological tools that help SMEs take advantage of Data Science in relation to Marketing for effective Customer Knowledge Management within CRM business processes. Furthermore, it will explore the organizational factors, including management approaches and routines, which support smooth implementation of digital transformation in marketing.

\section{Research Methodology}

The research methodology is based on a qualitative approach, by adopting the case study research method (Yin, 2003). The choice of the case method was motivated by the fact that the study of the role of technological tools, Data Science in marketing, and organizational capabilities for successful digital transformation in startups and SMEs represents a contemporary phenomenon (Nambisan,2017; Li et al.,2018; Rejeb, A. et al., 2020) in a context of real life (Yin, 2003). In addition, this method allows to study the phenomenon in more depth than a large-scale survey or an experimental research (Dufour et al., 1991).

\subsection{Presentation of the Case Study}

"Orcas" is an EdTech startup, established in Egypt in 2013, as an online marketplace that allows parents to search and find trusted, trained, and experienced tutors and language instructors in their area. tutors. It aims to make parents' lives easier by providing a safe, efficient, and educational services. The company has 45 employees and mainly operates in Cairo and Alexandria in Egypt. "Orcas" has over 2000 trained, experienced and reliable tutor profiles that have been background checked and received ratings and reviews from previous clients. Parents get to choose based on the relevant location, age group, experience, and language of the tutor from a given wide range of profiles. "Orcas" goal is to create experiences that foster the growth and development of children as well as ensuring a safe environment for the children and the team of instructors similar to the environment that is 
present at home. "Orcas" has proved that it is a successful application as it achieved a major growth (300\%) in 2019 after Algebra Venture invested \$500,000 in their mobile application. "Orcas" realized this success by deploying simple technological tools enabling them to take advantage of Data Science in relation to marketing and capitalize on its customer knowledge. That makes this case highly relevant for the research objective.

\subsection{Data Collection}

Two different techniques of data collection have been used: semi-structured interviews as well as direct observation:

\subsubsection{Semi-structured interviews}

14 interviews were carried out with the core functions involved in the processes of the Customer Relationship Management (Marketing, Sales, Customer Service). A part of the interview guide was dedicated for the technological tools used by "Orcas" to smoothen the CKM process therefore results in an effective CRM.

\subsubsection{Direct observation}

Two-months observational study (March and April 2020) was also conducted to observe the usage of the technological tools, how IT is aligned with the CRM business needs and the organizational factors that support the Customer Knowledge Management process.

Secondary data (e.g., archival documents, website, mobile application, and social media platforms) were also accessed to extend our empirical analysis.

\subsection{Data Analysis}

Most interviews were recorded (a total of 7 hours). They were translated in order to carry out the coding and the analysis of the data. The authors investigated the technological tools supporting Customer Knowledge Management through the CRM business processes, the organizational factors that support the CKM process and thus the alignment between IT infrastructure and CRM business processes.

\section{Research Findings}

"Orcas" used effectively relevant technological tools taking advantage of Data Science in relation to Marketing by extracting valuable customer knowledge to improve its CRM effectiveness. "Orcas" has a well-founded digital platform such as Facebook, Instagram, and LinkedIn. Not to mention, it has an online presence through its mobile application that can be found in Google Play and Apple Store, and website". At "Orcas", experience proved that online marketing activities are effective such as Google ads, Search Engine Optimization (SEO), Facebook ads, content marketing, and App Store Optimization (ASO). "Orcas"

\footnotetext{
${ }^{1}$ https://www.orcas.io/about-orcas
} 


\section{3rd International Academic Conference on MANAGEMENT and ECONOMICS}

managed to integrate Data Science to capitalize on customer knowledge through its online platforms to improve its Customer Relationship Management, leading to a proper selection of the technological tools that would support their customer centric approach and their business needs.

\subsection{Technological tools supporting Data Science in relation to Marketing and Customer Knowledge Management for effective CRM}

"Orcas" used multiple tools for proper Customer Knowledge Management and CRM Effectiveness. Tools include Zoho CRM which was mainly used to gather customers feedback to detect any problems or complaints, it is an essential tool for complaints management. Zoho CRM was also used to convert leads, boost sales, increase customer acquisition, and effectively manage customer information. Mix Panel was mainly used to track customers interactions and transactions through the mobile application and the website, in addition to analyzing the customers' responses through the survey forms and in-app tests; this data was then used to build customer reports and measure customer engagement. At "Orcas", Mix Panel was essentially used for offer management, lead management, and campaign management as well. Moreover, Tableau was used as a data visualization tool to support the analysis and visualization of data in a simple understandable and speedy manner. "Orcas" used it for data analysis and translating this data into an understandable format in the form of worksheets and dashboards. Extracted data was then saved and shared between different departments in the form of Google sheets and documents on Google Drive. For "Orcas", Google Dashboards was an adequate tool to support managing the business processes between different departments as well as managing feedback and concerns from customers. To support better CRM, Slack was used for easy and smooth internal communication among departments and to share customer knowledge. Moreover, only one information system was used in the form of Google sheets and documents on Google Drive. Both include the results and reports extracted from the previously mentioned IT tools, shared between all departments and could be easily accessed. This information system eases the knowledge flow between different departments and accelerates their work which leads to an effective CRM process.

Data mining and data analysis are significant KM techniques that ease the KM process for employees and supports the CRM processes through accurate, clear and organized reports and graphs. Therefore, "Orcas" usage of analytical tools such as Mix Panel and Tableau help in tracking received requests (Offer management), conversion rate (Lead management), customers' engagement and feedback (Campaign management). Through data mining they gather the customers' feedback and reviews on the application to stand on the level of satisfaction to a specific service and take immediate remedial actions. Also, those KM techniques help the employees gather organized information and insights from the customers' transaction history, so their customer knowledge is enhanced and met adequately. Those used tools ease the data analysis process and enhance the CKM, moreover reaching an effective CRM that helps in maintaining long-term relationships with customers.

\subsection{Alignment of technological tools with CRM Business Processes}

"Orcas" integrated its customer knowledge to support its CRM business processes effectively. At "Orcas", the process of lead and offer management uses customer knowledge and achieve 


\section{3rd International Academic Conference on MANAGEMENT and ECONOMICS}

CRM effectiveness, which is consequently reflected in increase number of requests, increase prospects quality, increase the number of users (Conversion rate), maintain customer satisfaction, and enhance offered services. Moreover, for campaign management, "Orcas" uses customer knowledge to collect leads, provide quality tutors, build brand image, increase users' satisfaction, and build customer-oriented company. As for the customer service reflected in contract, service, complaint, and opportunity management, "Orcas" uses customer knowledge to improve service process and increase customer satisfaction and retention. Table 1 represents a summary on how technological tools are aligned with the CRM business processes to manage customer knowledge for effective CRM at "Orcas".

Table 1: Alignment of technological tools with CRM Business Processes

\begin{tabular}{|c|c|c|}
\hline Technological tools & CRM Business Processes & CRM Effectiveness \\
\hline Zoho CRM & $\begin{array}{l}\text { Gather feedback from the } \\
\text { customers to stand on any } \\
\text { problems/complaints faced. } \\
\text { (Complaint Management) } \\
\text { Furthermore, it is used to } \\
\text { evaluate applicants fit for } \\
\text { tutoring. }\end{array}$ & $\begin{array}{l}\text { Address and solve swiftly } \\
\text { issues faced by the } \\
\text { customers. } \\
\text { Providing the best tutors to } \\
\text { satisfy customers' needs and } \\
\text { provide excellent levels of } \\
\text { customer satisfaction. }\end{array}$ \\
\hline $\begin{array}{l}\text { Mix Panel } \\
(2018)\end{array}$ & $\begin{array}{l}\text { Track customer transactions, } \\
\text { requests, and engagement. } \\
\text { (Lead and Offer Management) } \\
\begin{array}{l}\text { Build customer reports and } \\
\text { measure }\end{array} \\
\text { engagement. } \\
\begin{array}{l}\text { Provide useful information } \\
\text { prior launching a marketing } \\
\text { campaign } \\
\text { Management) }\end{array} \\
\end{array}$ & $\begin{array}{l}\text { Encourages customers to } \\
\text { place requests and use } \\
\text { "Orcas" by providing them } \\
\text { information about the best } \\
\text { tutors, new categories, and } \\
\text { packages available that } \\
\text { satisfy their needs to } \\
\text { improve customer } \\
\text { experience and } \\
\text { consequently retention rate. }\end{array}$ \\
\hline $\begin{array}{l}\text { Tableau } \\
(2019)\end{array}$ & $\begin{array}{l}\text { Used for data analysis and } \\
\text { translating the data in the form } \\
\text { of worksheets and dashboards. } \\
\text { Helps top management in the } \\
\text { decision-making process and } \\
\text { improve service when } \\
\text { relevant. (Opportunity } \\
\text { Management) }\end{array}$ & $\begin{array}{l}\text { Improve the service level } \\
\text { leading to better customer } \\
\text { satisfaction and retention. }\end{array}$ \\
\hline Slack & $\begin{array}{l}\text { Provides an easy and smooth } \\
\text { internal communication } \\
\text { among departments along with } \\
\text { sharing information. }\end{array}$ & $\begin{array}{ll}\begin{array}{l}\text { Accelerates users' } \\
\text { improve }\end{array} & \text { cust and } \\
\text { experience. } & \end{array}$ \\
\hline Google drive & $\begin{array}{l}\text { Easily can access and share } \\
\text { Google sheets and documents } \\
\text { which ensures knowledge } \\
\text { sharing and accelerate the } \\
\text { business process. }\end{array}$ & $\begin{array}{l}\text { Effectively manage } \\
\text { customer requests, improve } \\
\text { responsiveness, and enrich } \\
\text { the customer experience }\end{array}$ \\
\hline
\end{tabular}




\subsection{Organizational Factors supporting Digital Transformation in Marketing}

At "Orcas" it is not only about technological tools and relevant digital platforms; "Orcas" is adapting a customer centric approach, where the customer is at the heart of the business. Some important organizational factors were essential to lead its digital transformation journey.

\subsubsection{Culture: Customer-orientation}

Customer-orientation consists a continuous understanding of the needs of current and potential target customers and the use of this knowledge (Narver \& Slater, 1990). "Orcas" shared a customer-oriented culture; all decisions and marketing activities revolve around customer's information, feedback, and ideas.

\subsubsection{Strategy: Top management support}

Top management support was reflected in increased investment into technological tools and infrastructure. Continuous technical training for employees made the CRM process more efficient and deliver the best results to the end users (the customers). "Orcas" top management are constantly supporting their employees and try to facilitate the knowledge sharing process. At first, they were only using Zoho CRM and Mix Panel systems, then the top management decided to increase their investment in technological tools and added the subscription of Tableau. The company now invest nearly $2000 \$$ annually on technological tools.

\subsubsection{Structure: Team structure, cross functionally and evaluation systems}

"Orcas" is a startup which follows a team structure in each department to encourage knowledge sharing between team members and the different functions as well. The marketing department helps the sales department collect leads through surveys and then send those leads to the sales department in order to contact them and encourage those leads to take the requested action. The sales team collects information about the customer mainly through the app as the user signs up. The information includes name, email, phone number, number of children, etc. also, as the user navigates the app and starts searching for what suits them, the sales team follow up the categories they searched for and their interests. Information is then passed from the sales teams to the customer service team in order to help them better understand the customers and accelerate their services.

Moreover, evaluation and reward systems are implemented in "Orcas" to encourage employees to share customer knowledge and to do their best in order to satisfy and retain the customers. These systems are mainly based on the customers' satisfaction and ratings for each tutor. These organizational factors on the culture, strategy and structure levels supported the CKM and help for better alignment between IT infrastructure and business needs (CRM business processes). 


\section{Discussion and Conclusion}

The case study of " Orcas"' demonstrated how a small-scale business- with inadequate and limited resources- can capitalize on Data Science and technology to effectively manage the flow of customer knowledge and smoothly implement digital transformation in marketing. The case study presented how the CRM functions leverage the Customer Knowledge Management cycle through its technological tools to create value. Therefore, SMEs can benefit from simple tools and applications such as Zoho CRM, Mix Panel analytical tool, Google Dashboard, Tableau as a data visualization tool used for Business Intelligence. As stated by Ogbuokiri et al. (2015), big data solutions must demonstrate simplicity, and cost must be relevant and priced right for the needs and only the capabilities that will be used by SMEs.

Customer Knowledge is an essential organizational resource. It is showed that "Orcas" has applied the Customer Knowledge through the CRM business processes to enable the startup to sustain its competitive advantage based on Data Science and knowledge management. Customer Knowledge Management through relevant technological tools has enabled them to improve their marketing, sales strategies, customer service, in addition to some organizational factors that support the alignment between IT infrastructure and CRM business needs enabling smooth implementation of digital transformation in marketing.

There is no doubt that information technologies such as workflow management systems and data mining techniques can facilitate KM processes (Chen \& Chen, 2004; Wong \& Aspinwall, 2005). CRM systems make it easier to acquire, analyze, transfer and use knowledge related to customer behavior (Zablah et al., 2004; Salojärvi et al., 2010). Beside the technology part, in line with previous studies, the organizational factors that support the CKM at "Orcas" were cultural, strategic and structural factors. A large number of studies (Nguyen et al., 2007; Garrido-Moreno and Padilla-Meléndez, 2011; Kaoud, 2018) revealed that the organizational variables; customer orientation and organizational culture of collaboration and knowledge sharing, strategy and top management support, organizational structure and inter-functional integration, are the key success factors of CRM. These organizational factors mediate the impact of other factors including KM capabilities and technological support on the success of CRM (Garrido -Moreno \& Padilla-Meléndez, 2011; Khosravi \& Hussin, 2016). Startups and SMEs can leverage the potential of digital transformation in marketing by having a holistic management approach towards CKM.

This research has contributed to the need of further evidence on how entrepreneurs of SMEs drove digital transformation in their companies (Li et al., 2018), along with the role of digital technologies in entrepreneurial pursuits (Nambisan, 2017) and big data in marketing activities (Rejeb, A. et al., 2020). From a managerial perspective, this study will help startups and SMEs to implement successful digital transformation in marketing. The case study of "Orcas" as a successful startup revealed certain best practices in the areas of KM and CRM.

The study does have some limitations, many of which highlight potential opportunities for future research. The study is based on a single case according to the research objective to examine in-depth the evolving role of Data Science in relation to Marketing in startups and 


\section{3rd International Academic Conference on MANAGEMENT and ECONOMICS}

SMEs and thus explore the organizational factors which support smooth implementation of digital transformation in marketing. The research is focused specifically on an Egyptian EdTech startup, so studies at the international level and within other industries would be useful to test the generalization of the findings from other countries and industries. Quantitative studies at large scale would be also interesting.

\section{References}

Achrol, R. S., \& Kotler, P. (1999). Marketing in the network economy. Journal of marketing, 63(4_suppl1), 146-163.

Aral, S., \& Weill, P. (2007). IT assets, organizational capabilities, and firm performance: How resource allocations and organizational differences explain performance variation. Organization Science, 18(5), 763-780.

Barney, J., Wright, M., \& Ketchen, D. J. Jr. (2001). The resource-based view of the firm: Ten years after 1991. Journal of Management, 27(6), 625-641.

Barutçu, M. T. (2017). Big Data Analytics for Marketing Revolution. Journal of Media Critiques, 3(11), 163-171.

Beijerse, R. P. (1999). Questions in knowledge management: Defining and conceptualising a phenomenon. Journal of Knowledge Management, 3(2), 94-110.

Bendle, N. T., \& Wang, X. S. (2016). Uncovering the message from the mess of big data. Business horizons, 59(1), 115-124.

Blosch, M. (2000). Customer knowledge. Knowledge and Process Management, 7(4), 265268.

Campbell, H. M. (2006, September). The role of organizational knowledge management strategies in the quest for business intelligence. In 2006 IEEE International Engineering Management Conference (pp. 231-236). IEEE.

Chen, Q. and Chen, H.M. (2004), "Exploring the success factors of eCRM strategies in practice", Journal of Database Marketing \& Customer Strategy Management,11(4), 333343.

Chen, J. E., Pan, S. L., \& Ouyang, T. H. (2014). Routine reconfiguration in traditional companies' e- commerce strategy implementation: A trajectory perspective. Information Management, 51(2), 270-282.

Cui, M., \& Pan, S. L. (2015). Developing focal capabilities for e- commerce adoption: A resource orchestration perspective. Information Management, 52(2), 200-209

Dalkir, K., \& Liebowitz, J. (2011). Knowledge management in theory and practice. Cambridge, USA: MIT press.

Dehning, B., Richardson, V. J., \& Zmud, R. W. (2003). The value relevance of announcements of transformational information technology investments. MIS Quarterly, 27(4), 637-65

Deloitte. (2018). Knowledge Management \& Big Data Making Smart Enterprise a Reality [Online].Available:https://www2.deloitte.com/content/dam/Deloitte/in/Documents/technology -media-telecommunications/in-tmt-knowledge-management-and-big-data-noexp.pdf

Deloitte.(2020). Tech $\quad$ Trends 2020 [Online]. Available: https://www2.deloitte.com/content/dam/Deloitte/pt/Documents/techtrends/TechTrends2020.p $\underline{\mathrm{df}}$ 


\section{3rd International Academic Conference on MANAGEMENT and ECONOMICS}

Dholakia, N., Zwick, D., and Denegri-Knott, J.(2010). Technology, Consumers, and Marketing Theory, In: The SAGE Handbook of Marketing Theory, SAGE.

Dufour, S., Fortin, D., \& Hamel, J. (1991). L'enquête de terrain en sciences sociales: l'approche monographie et les méthodes qualitatives. Montréal, Canada: Les Éditions SaintMartin

Gantz, J., \& Reinsel, D. (2012). The digital universe in 2020: Big data, bigger digital shadows, and biggest growth in the far east. IDC iView: IDC Analyze the future, 2007(2012), 1-16.

Garrido-Moreno, A., \& Padilla-Meléndez, A. (2011). Analyzing the impact of knowledge management on CRM success: The mediating effects of organizational factors. International Journal of Information Management, 31(5), 437-444.

Gibbert, M., Leibold, M., \& Probst, G. (2002). Five styles of customer knowledge management, and how smart companies use them to create value. European Management Journal, 20(5), 459-469

Gončarovs, P. (2017). Data analytics in crm processes: A literature review. Information Technology and Management Science, 20(1), 103-108.

Kaoud, M. (2018). Proposition d'un modèle organisationnel intégratif pour la gestion des connaissances clients: étude de cas approfondie (Doctoral dissertation, Nantes).

Kaoud, M. (2017). Investigation of Customer Knowledge Management: A Case Study Research. International Journal of Service Science, Management, Engineering, and Technology (IJSSMET), 8(2), 12-22.

Karakostas, B., Kardaras, D., \& Papathanassiou, E. (2005). The state of CRM adoption by the financial services in the UK: An empirical investigation. Information \& Management, 42(6), 853-863

Khosravi, A. et Hussin, A.R.C. (2016), "Customer Knowledge Management: Development Stages and Challenges", Journal of Theoretical and Applied Information Technology,91,(2), $264-274$.

Lei, Y., \& Tang, B. (2005). Study on KM based CRM system. Proceedings of the Sixth Wuhan International Conference on E-Business-Innovation Management Track.

Li, L., Su, F., Zhang, W., \& Mao, J. Y. (2018). Digital transformation by SME entrepreneurs: A capability perspective. Information Systems Journal, 28(6), 1129-1157.

Lucas Jr, H., Agarwal, R., Clemons, E. K., El Sawy, O. A., \& Weber, B. (2013). Impactful research on transformational information technology: an opportunity to inform new audiences. Mis Quarterly, 371-382.

Luggen, M. (2004). Technology and innovation management in new technology-based firms: Introducing the PockeTM concept (Doctoral dissertation, ETH Zurich).

Matt, C., Hess, T., \& Benlian, A. (2015). Digital transformation strategies. Business \& Information Systems Engineering, 57(5), 339-343.

Mithas, S., Krishnan, M. S., \& Fornell, C. (2005). Why do customer relationship management applications affect customer satisfaction? Journal of Marketing, 69(4), 201-209.

Nambisan, S. (2017). Digital entrepreneurship: Toward a digital technology perspective of entrepreneurship. Entrepreneurship Theory and Practice, 41(6), 1029-1055.

Narver, J. C., \& Slater, S. F. (1990). The effect of a market orientation on business profitability. Journal of marketing, 54(4), 20-35. 


\section{3rd International Academic Conference on MANAGEMENT and ECONOMICS}

Nguyen B., et Mutum, D.S. (2012), "A review of customer relationship management: successes, advances, pitfalls and futures", Business Processes Management Journal, 18(3), 400- 419.

Ogbuokiri, B. O., Udanor, C. N., \& Agu, M. N. (2015). Implementing bigdata analytics for small and medium enterprise (SME) regional growth. IOSR Journal of Computer Engineering, 17(6), 35-43.

Pantano, E., Giglio, S., \& Dennis, C. (2019). Making sense of consumers' tweets. International Journal of Retail \& Distribution Management, 47(9),915-927.

Parirokh, M., Daneshgar, F., \& Fattahi, R. (2009). A theoretical framework for development of a customer knowledge management system for academic libraries. Proceedings of the World Library and Information Congress: 75th IFLA General Conference and Council (WLIC '09), Milan, Italy.

Penrose, E. T. (1959). The Theory of the Growth of the Firm. New York: John Wiley \& Sons.

Porter, M. E. (1985). Competitive advantage: creating and sustaining superior performance. New York, USA: Free Press.

Piercy, N. (1984). The impact of new technology on services marketing. The Service Industries Journal, 4(3), 193-204.

Rejeb, A., Rejeb, K., \& Keogh, J. G. (2020). Potential of Big Data for Marketing: A Literature Review. Management Research and Practice, 12(3), 60-73.

Salmador, M. P., \& Bueno, E. (2007). Knowledge creation in strategy-making: Implications for theory and practice. European Journal of Innovation Management, 10(3), 367-390.

Salojärvi, H., Sainio, L.M., Tarkiainen, A. (2010), "Organizational factors enhancing customer knowledge utilization in the management of key account relationships", Industrial Marketing Management, 39 (8), 1395-1402.

Salomann, H., Dous, M., Kolbe, L., \& Brenner, W. (2005). Rejuvenating Customer Management: How to Make Knowledge For, From and About Customers Work. European Management Journal, 23(4), 392-403

Schmid, R. (2001). Eine Architektur für Customer Relationship Management und Prozessportale bei Banken [Doctoral dissertation]. Difo-Druck

Sofianti, T. D., Suryadi, K., Govindaraju, R., \& Budhi, P. (2009). Customer Knowledge Management In New Product Development. Proceedings of the scientific conference (APIEMS'09) (pp. 1268-1279)

Soroka, A., Liu, Y., Han, L., \& Haleem, M. S. (2017). Big data driven customer insights for SMEs in redistributed manufacturing. Procedia CIRP, 63, 692-697.

Stefanou, C. J., Sarmaniotis, C., \& Stafyla, A. (2003). CRM and customer-centric knowledge management: An empirical research. Business Process Management Journal, 9(5), 617-634.

Tan, B., Pan, S. L., Lu, X., \& Huang, L. (2015). The role of IS capabilities in the development of multi- sided platforms: The digital ecosystem strategy of Alibaba.Com. Journal of the Association for Information Systems, 16(4), 248-280.

Uğur, N. G., Turan, A. H. (2018) Managing Big Data: A Research on Adoption Issues. Paper presented at the Fifth International Management Information Systems Conference

Vassileva, B. (2017). Marketing 4.0: How technologies transform marketing organization. Óbuda university e-Bulletin, 7(1), 47.

Venkatraman, N. (1994). IT- enabled business transformation: From automation to business scope redefinition. Sloan Management Review, 35(2), 73-87 
Wernerfelt, B. (1984). A resource- based view of the firm. Strategic Management Journal, 5(2), 171-180.

Wong, K. Y., et Aspinwall, E. (2005), "An empirical study of the important factors for knowledge management adoption in the SME sector", Journal of Knowledge Management, vol. 9, n³, p. 64- 82 .

Winer, R. S. (2001). A framework for customer relationship management. California Management Review, 43(4), 89-105.

Yin, R. K. (2003). Case study research design and methods (3rd ed.). Sage Publications.

Zablah, A.R., Bellenger, D.N, Johnston, W.J. (2004). "An evaluation of divergent perspectives on customer relationship management: Towards a common understanding of an emerging phenomenon", Industrial Marketing Management. 33(6), 475-489.

Zhao, X., Huo, B., Flynn, B. B., \& Yeung, J. H. Y. (2008). The impact of power and relationship commitment on the integration between manufacturers and customers in a supply chain. Journal of Operations Management, 26(3), 368-388.

Zeng, J., \& Glaister, K. W. (2018). Value creation from big data: Looking inside the black box. Strategic Organization, 16(2), 105-140. 